\title{
Association between Possibility of Purchasing Cigarettes and E-cigarette Experience among Korean Adolescent Smokers
}

\author{
Jae-Hyun Kim ${ }^{1,2}$, Jin-Won Noh ${ }^{3,4}$, Sun-Jung Kim ${ }^{5}$, Jeoung A Kwon ${ }^{6}$, Young Choi ${ }^{7}$, Ki-Bong Yoo ${ }^{8,9, *}$ \\ 'Department of Health Administration, Dankook University, Cheonan, Korea \\ ${ }^{2}$ Institute of Health Promotion and Policy, Dankook University, Cheonan, Korea \\ ${ }^{3}$ Department of Healthcare Management, Eulji University, Seongnam, Korea \\ ${ }^{4}$ Institute of Global Healthcare Research, Eulji University, Seongnam, Korea \\ ${ }^{5}$ Department of Health Administration, Soonchunhyang University, Asan, Korea \\ ${ }^{6}$ National Cancer Control Institute, National Cancer Center, Goyang, Korea \\ ${ }^{7}$ Department of Biomedical Informatics, Ajou University School of Medicine, Suwon, Korea \\ ${ }^{8}$ Department of Health Administration, Yonsei University College of Health Sciences, Wonju, Korea \\ ${ }^{9}$ Department of Information \& Statistics, Yonsei University College of Health Sciences, Wonju, Korea
}

Background: To aim of this study was to examine the association between perceived possibility of purchasing cigarettes and e-cigarette experience among adolescents who currently smoke cigarettes.

Methods: Data were derived from the Korea Youth Risk Behavior Web-Based Survey; a total of 29,169 current smokers participated. The dependent variable was e-cigarette experience in the previous month. Analyses included $\chi^{2}$ test and survey logistic regression.

Results: A perceived easy possibility of purchasing cigarettes increased the odds of e-cigarette experience (odds ratio, 1.19; 95\% confidence interval, 1.07-1.33) compared to when it was perceived as impossible. An easy possibility of purchasing cigarettes increased the odds of e-cigarettes experience among males aged 12-15 or 17 years compared to when it was impossible to purchase cigarettes.

Conclusion: A perceived easy possibility of purchasing cigarettes was more likely to increase e-cigarette experience among adolescents. Laws restricting adolescents' access to e-cigarettes must be strengthened.

Keywords: Adolescent; Electronic Nicotine Delivery Systems; Cigarette Purchase; Smoking

Received: February 14, 2017, Revised: July 22, 2017, Accepted: July 27, 2017

${ }^{*}$ Corresponding Author: Ki-Bong Yoo https://orcid.org/0000-0002-2955-6948

Tel: +82-33-760-2458, Fax: +82-33-760-2519, E-mail: kb53545@gmail.com 


\section{INTRODUCTION}

Smoking is one of the most significant risk factors for various cardiovascular diseases, cancers, and respiratory diseases worldwide. ${ }^{1-3)}$ In Korea, smoking reportedly causes more than 46,000 deaths a year and accounts for $18.7 \%$ of total deaths. ${ }^{4)}$ In many countries, adult smokers first use tobacco during adolescence. Therefore, interventions to prevent adolescent tobacco use at this developmental milestone could potentially decrease nicotine addiction adverse health outcomes. ${ }^{5)} \mathrm{Al}$ though adolescents may believe that they can quit using tobacco at any time when they begin smoking, an estimated $70 \%$ of adolescent smokers continue smoking regularly into adulthood. ${ }^{6}$

As of 2013, Korea had a very high adult male smoking rate (48.5\%) among Organization for Economic Cooperation and Development countries. ${ }^{7}$ Furthermore, in 2016, it was determined that a total of $9.6 \%$ of male adolescents and $2.7 \%$ of female adolescents aged $12-17$ were smokers. ${ }^{8)}$ That said, smoking rates have decreased from those reported in 2009. However, there has been an increase in e-cigarette experience since 2011, when the government began to compile statistics on usage rates. ${ }^{9}$ )

There are many opinions regarding e-cigarette use. In the United Kingdom, e-cigarette use is considered better than traditional nicotine replacement therapy (NRT) to help smoking reduction or cessation and does not require a prescription. ${ }^{10)}$ However, the World Health Organization and U.S. Food and Drug Administration announced that ecigarettes have not been proven safe and effective compared to NRT. ${ }^{11)}$ One hypothesis is that the e-cigarettes act as a gateway to smoking regular cigarettes. ${ }^{12)}$ One recent study supported this hypothesis that there is a positive correlation between e-cigarette use frequency and cigarette smoking among Korean adolescents. ${ }^{13)}$ E-cigarettes may also cause adolescents (especially those who already smoke) to believe that tobacco products are easily accessible.

Researchers have reported that e-cigarettes have negative effects on adolescents' brain development and carry the risk of addiction. ${ }^{14)} \mathrm{A}$ report from the U.S. Department of Health and Human Services mentioned that e-cigarette use causes exposure to nicotine, carbonyl compounds, and volatile organic compounds, which are known to induce adverse health effects, and that e-cigarette aerosol is not harmless. ${ }^{15)}$

E-cigarette products can be purchased both online and offline, whereas tobacco cannot be purchased online in Korea. Consequently, it is comparatively easy to buy e-cigarettes. Previous findings have shown that increased cigarette accessibility raises adolescents' risk of smoking and that adolescents who smoke may be more likely to perceive that cigarettes are easily accessible. ${ }^{16-18)}$ Doubeni et al. ${ }^{19)}$ in 2009 stated that the cigarette accessibility is the gateway for all risk factors that contribute to adolescent smoking. Therefore, we must identify Korean adolescents' perceptions of the easy purchase of cigarettes and the e-cigarette experience. If adolescents can easily purchase cigarettes, they know a bypass strategy to purchase or obtain cigarettes from stores as well as e-cigarettes. Those who can easily purchase cigarettes are likely to have more experiences with e-cigarettes.
Consequently, the objective of this study was to identify the association between the possibility of purchasing cigarettes and e-cigarette experience among currently smoking adolescents. Thus, identifying factors associated with e-cigarette experience is imperative and assists public health professionals and decision makers with prioritizing and implementing effective intervention strategies to reduce and prevent adolescent tobacco use.

\section{METHODS}

\section{Sample}

The Korea Youth Risk Behavior Web-Based Survey (KYRBWS) is a nationwide web-based survey conducted by the Korea Centers for Disease Control and Prevention to evaluate Korean adolescents' (middle and high school students) health behaviors. We analyzed pooled cross-sectional data from a 4-year period. Data for this study were obtained from the KYRBWS each year from 2011 to 2014 . The study samples included 75,643 students in 2011, 74,816 in 2012, 72,435 in 2013, and 72,060 in 2014 . The response rates were $95.5 \%$ in 2011, 96.4\% in $2012,96.4 \%$ in 2013 , and $97.2 \%$ in 2014. Students from all middle and high schools in Korea were selected from 400 middle schools and 400 high schools using a two-stage stratified cluster sampling method. The population was stratified by 43 regional and school-type variables and the sample was selected in two stages: school (first sampling unit) and class (second sampling unit). Patient records and information was anonymized and de-identified prior to the analysis.

This study included only current smokers who indicated that they had smoked in the past month. The total number of adolescent smokers was 30,751: 8,988 students in 2011, 8,362 in 2012, 7,094 in 2013, and 6,307 in 2014. After the exclusion of adolescents for whom data were missing, 29,169 subjects were included in the final data analysis.

\section{Study Variables}

The dependent variable is e-cigarette experience; specifically, whether current smokers had used e-cigarettes within the past month. Thus, we considered an adolescent a current e-cigarette smoker if he or she had smoked an e-cigarette within the past month.

Sociodemographic characteristics such as age, sex, household economic status, academic performance, spending money per week, sexual activity experience, alcohol use, drug use, exercise, self-rated health, and obesity were included as covariates. Adolescent age groups included participants aged 12-13, 14, 15, 16, 17, and 18 years. Since there were only a few 12-year-olds $(n=561)$, participants aged 12 and 13 years were combined into a single group. Household economic status was classified as low, middle, or high. Academic performance was classified into low, middle, and high groups. Both household economic status and academic performance were evaluated using self-reported questions. Low and middle-low were combined into the low group. Similarly, high and middle-high were combined into the high group. Weekly spending money was categorized into \$0-9.99, \$10-29.99, and more than $\$ 30$ per week. Alcohol use was evaluated using the ques- 
Table 1. Participants' general characteristics

\begin{tabular}{|c|c|c|c|c|}
\hline Characteristic & Current smokers (total) & No e-cigarette experience & E-cigarette experience & P-value \\
\hline Possibility of purchasing cigarettes & & & & $<0.001$ \\
\hline Have not tried & 8,108 & 6,996 (86.3) & $1,112(13.7)$ & \\
\hline Impossible & 2,821 & $2,171(77.0)$ & $650(23.0)$ & \\
\hline Difficult & 2,703 & $1,932(71.5)$ & $771(28.5)$ & \\
\hline Easy & 15,537 & $10,236(65.9)$ & $5,301(34.1)$ & \\
\hline No. of cigarettes per day & & & & $<0.001$ \\
\hline$\leq 1$ & 7,496 & 6,664 (88.9) & $832(11.1)$ & \\
\hline $2-5$ & 9,451 & $7,256(76.8)$ & 2,195 (23.2) & \\
\hline $6-9$ & 6,575 & $4,246(64.6)$ & $2,329(35.4)$ & \\
\hline$\geq 10$ & 5,647 & $3,169(56.1)$ & $2,478(43.9)$ & \\
\hline Cigarettes access method & & & & $<0.001$ \\
\hline Get from friends & 10,267 & $8,185(79.7)$ & $2,082(20.3)$ & \\
\hline Buy in a store & 14,043 & $9,218(65.6)$ & $4,825(34.4)$ & \\
\hline Other* & 4,859 & $3,932(80.9)$ & $927(19.1)$ & \\
\hline Smoking cessation trial & & & & $<0.001$ \\
\hline No & 8,512 & $6,543(76.9)$ & $1,969(23.1)$ & \\
\hline Yes & 20,657 & $14,792(71.6)$ & $5,865(28.4)$ & \\
\hline Anti-smoking education experience & & & & $<0.001$ \\
\hline No & 11,314 & $8,209(72.6)$ & $3,105(27.4)$ & \\
\hline Yes & 17,855 & $13,126(73.5)$ & $4,729(26.5)$ & \\
\hline Age $(y)$ & & & & $<0.001$ \\
\hline $12-13$ & 2,619 & $2,219(84.7)$ & $400(15.3)$ & \\
\hline 14 & 3,676 & $2,849(77.5)$ & $827(22.5)$ & \\
\hline 15 & 5,498 & $3,931(71.5)$ & $1,567(28.5)$ & \\
\hline 16 & 6,685 & $4,707(70.4)$ & $1,978(29.6)$ & \\
\hline 17 & 7,301 & $5,219(71.5)$ & $2,082(28.5)$ & \\
\hline 18 & 3,390 & $2,410(71.1)$ & $980(28.9)$ & \\
\hline Sex & & & & $<0.001$ \\
\hline Female & 7,326 & 6,134 (83.7) & $1,192(16.3)$ & \\
\hline Male & 21,843 & $15,201(69.6)$ & 6,642 (30.4) & \\
\hline Household economic status & & & & $<0.001$ \\
\hline Low & 8,845 & $6,553(74.1)$ & 2,292 (25.9) & \\
\hline Middle & 12,832 & $9,549(74.4)$ & $3,283(25.6)$ & \\
\hline High & 7,492 & $5,233(69.8)$ & $2,259(30.2)$ & \\
\hline Academic performance & & & & $<0.001$ \\
\hline Low & 17,052 & $12,317(72.2)$ & $4,735(27.8)$ & \\
\hline Middle & 6,424 & $4,781(74.4)$ & $1,643(25.6)$ & \\
\hline High & 5,693 & $4,237(74.4)$ & $1,456(25.6)$ & \\
\hline Money spent per week (\$) & & & & $<0.001$ \\
\hline $0-9.99$ & 4,869 & $3,943(81.0)$ & $926(19.0)$ & \\
\hline 10-29.99 & 11,096 & $8,362(75.4)$ & $2,734(24.6)$ & \\
\hline$\geq 30$ & 13,204 & $9,030(68.4)$ & $4,174(31.6)$ & \\
\hline Sexual activity experience & & & & $<0.001$ \\
\hline No & 23,095 & $17,650(76.4)$ & $5,445(23.6)$ & \\
\hline Yes & 6,074 & $3,685(60.7)$ & $2,389(39.3)$ & \\
\hline Alcohol use & & & & $<0.001$ \\
\hline No & 19,093 & $13,247(69.4)$ & $5,846(30.6)$ & \\
\hline Yes & 10,076 & 8,088 (80.3) & $1,988(19.7)$ & \\
\hline Drug use & & & & $<0.001$ \\
\hline No & 28,090 & 20,752 (73.9) & 7,338 (26.1) & \\
\hline Yes & 1,079 & $583(54.0)$ & $496(46.0)$ & \\
\hline Exercise & & & & $<0.001$ \\
\hline No & 9,214 & 6,983 (75.8) & 2,231 (24.2) & \\
\hline $1-4$ times/wk & 13,418 & $9,802(73.1)$ & $3,616(26.9)$ & \\
\hline 5 times/wk & 6,537 & $4,550(69.6)$ & $1,987(30.4)$ & \\
\hline
\end{tabular}


Table 1. Continued

\begin{tabular}{|c|c|c|c|c|}
\hline Characteristic & Current smokers (total) & No e-cigarette experience & E-cigarette experience & P-value \\
\hline Self-rated health & & & & 0.019 \\
\hline Poor & 2,641 & 1,929 (73.0) & $712(27.0)$ & \\
\hline Normal & 7,464 & $5,554(74.4)$ & $1,910(25.6)$ & \\
\hline Good & 19,064 & $13,852(72.7)$ & $5,212(27.3)$ & \\
\hline Obesity & & & & $<0.001$ \\
\hline Underweight & 2,053 & 1,449 (70.6) & 604 (29.4) & \\
\hline Normal & 23,482 & $17,130(72.9)$ & 6,352 (27.1) & \\
\hline Overweight & 601 & $499(83.0)$ & $102(17.0)$ & \\
\hline Obese & 3,033 & $2,257(74.4)$ & $776(25.6)$ & \\
\hline Year & & & & $<0.001$ \\
\hline 2011 & 8,564 & 6,244 (72.9) & $2,320(27.1)$ & \\
\hline 2012 & 7,980 & $6,173(77.4)$ & $1,807(22.6)$ & \\
\hline 2013 & 6,715 & $5,323(79.3)$ & $1,392(20.7)$ & \\
\hline 2014 & 5,910 & $3,595(60.8)$ & 2,315 (39.2) & \\
\hline Total & 29,169 & $21,335(73.1)$ & 7,834 (26.9) & \\
\hline
\end{tabular}

Values are presented as number (\%). P-values are results from the $\chi^{2}$ test.

*Pick up cigarettes on the road, get from adults, or find at home.

tion, "Have you consumed more than one glass of alcohol in the past month?" Drug use was identified using the question, "Have you ever purposefully consumed stimulants such as inhalants or drugs?" In addition, exercise was assessed using the question, "How many times did you exercise for more than 60 minutes during the past week?" In response, participants rated their exercise level as "no," "1-4 times a week," or " 5 or more times a week." Self-rated health was grouped as poor, normal, or good. Obesity was categorized as underweight (body mass index $[\mathrm{BMI}]<5$ th percentile for each age), normal (BMI in the 5 th to 85th percentile), overweight (BMI in the 85th to the 95th percentile for each age), and obese (BMI $\leq 95$ th percentile for each age) ${ }^{20)}$ Obesity was generated by SAS code from the KYRBWS guidebook. ${ }^{9)}$ Since pooled cross-sectional data were used, year was also included as a variable.

The possibility of purchasing cigarettes, cigarette access method, number of cigarettes smoked per day, smoking cessation trials, and anti-smoking education experience were included as independent variables. The possibility of purchasing cigarettes (ease of purchasing them) was evaluated using the question, "Is it difficult to buy cigarettes at a store?" Possible responses included "I have not tried to purchase cigarettes during the past month," "It is impossible to purchase cigarettes," "If I tried hard, I could purchase cigarettes," "If tried a little, I could purchase cigarettes," or "I could purchase cigarettes without any effort." We categorized the possibility of purchasing cigarettes as "have not tried," "impossible," "difficult," and "easy," respectively. (The "easy" category included "If tried a little, I could purchase cigarettes" and "I could purchase cigarettes without any effort.") Cigarette access method was categorized into "got cigarettes from friends," "bought cigarettes in a store," and "other." The "other" category included picking up cigarettes on the road, getting cigarettes from adults, or finding cigarettes in their homes.

\section{Data Analysis}

Both the $\chi^{2}$ test and multiple logistic regression analyses adjusted for smoking-related variables, socioeconomic status, health-risk behavioral variables, and year were used to analyze the association between adolescents' perceptions of the possibility of purchasing cigarettes and the e-cigarette experience. PROC SURVEYLOGISTIC (SAS Institute Inc., Cary, NC, USA) was used to apply the sampling design weights. All data are represented as number (\%), and statistical significance was set at $\mathrm{P}<0.05$. Odds ratios (ORs) and 95\% confidence intervals (CIs) were calculated. Statistical analyses were performed using SAS ver. 9.3 (SAS Institute Inc.).

\section{RESULTS}

Table 1 shows the participants' general characteristics. The total number of e-cigarette experiences was 7,834 (26.9\%). Although the number of current smokers decreased yearly, e-cigarette experience peaked in 2014. The easier the possibility of purchasing cigarettes, the greater the e-cigarette experiences.

Table 2 presents the association between independent variables and e-cigarette experience. After the adjustment for covariates, an easy possibility of purchasing cigarettes increased the odds of e-cigarette experience (OR, 1.19; 95\% CI, 1.07-1.33). Adolescents' anti-smoking education experience was non-significant. Additionally, the more cigarettes subjects smoked per day, the higher the OR for e-cigarette experience was. Compared to participants in the age group of 12-13 years, those in the age group of 14-15 years were significantly associated with an increased OR of e-cigarette experience. Specifically, the odds of use for 14-year-old participants were 1.24 times higher (95\% CI, 1.07-1.44), while the odds for 15-year-old participants were 1.29 times higher (95\% CI, 1.13-1.48). However, the odds of e-cigarette experience for 18-year-old participants were 0.81 times lower (95\% CI, $0.69-0.95)$. Additionally, completing a smoking cessation trial and dis- 
Table 2. Results of survey logistic regression analysis between independent variables and e-cigarette experience by current smokers

\begin{tabular}{|c|c|}
\hline Variable & E-cigarette experience \\
\hline \multicolumn{2}{|c|}{ Possibility of purchasing cigarettes } \\
\hline Have not tried & $0.74(0.66-0.83)$ \\
\hline Impossible & 1.00 \\
\hline Difficult & $1.07(0.94-1.22)$ \\
\hline Easy & $1.19(1.07-1.33)$ \\
\hline \multicolumn{2}{|l|}{ No. of cigarettes per day } \\
\hline$\leq 1$ & 1.00 \\
\hline $2-5$ & $1.84(1.67-2.02)$ \\
\hline $6-9$ & $2.93(2.65-3.25)$ \\
\hline$\geq 10$ & $3.87(3.47-4.32)$ \\
\hline \multicolumn{2}{|l|}{ Cigarettes access method } \\
\hline Get from friends & 1.00 \\
\hline Buy in a store & $1.06(0.98-1.15)$ \\
\hline Other ${ }^{\star}$ & $0.95(0.86-1.05)$ \\
\hline \multicolumn{2}{|l|}{ Smoking cessation trial } \\
\hline No & 1.00 \\
\hline Yes & $1.25(1.18-1.34)$ \\
\hline \multicolumn{2}{|c|}{ Anti-smoking education experience } \\
\hline No & 1.00 \\
\hline Yes & $0.99(0.93-1.05)$ \\
\hline \multicolumn{2}{|l|}{ Age (y) } \\
\hline $12-13$ & 1.00 \\
\hline 14 & $1.24(1.07-1.44)$ \\
\hline 15 & $1.29(1.13-1.48)$ \\
\hline 16 & $1.09(0.94-1.26)$ \\
\hline 17 & $0.93(0.80-1.07)$ \\
\hline 18 & $0.81(0.69-0.95)$ \\
\hline \multicolumn{2}{|l|}{ Sex } \\
\hline Female & 1.00 \\
\hline Male & $2.20(2.03-2.39)$ \\
\hline \multicolumn{2}{|l|}{ Household economic status } \\
\hline Low & 1.00 \\
\hline Middle & $0.99(0.92-1.06)$ \\
\hline High & $1.18(1.09-1.28)$ \\
\hline \multicolumn{2}{|l|}{ Academic performance } \\
\hline Low & 1.00 \\
\hline Middle & $0.94(0.87-1.01)$ \\
\hline High & $0.91(0.84-0.98)$ \\
\hline \multicolumn{2}{|c|}{ Spending money per week (\$) } \\
\hline $0-9.99$ & 1.00 \\
\hline 10-29.99 & $1.23(1.13-1.35)$ \\
\hline$\geq 30$ & $1.37(1.26-1.50)$ \\
\hline \multicolumn{2}{|l|}{ Sexual activity experience } \\
\hline No & 1.00 \\
\hline Yes & $1.41(1.32-1.52)$ \\
\hline \multicolumn{2}{|l|}{ Alcohol use } \\
\hline No & 1.00 \\
\hline Yes & $0.79(0.74-0.84)$ \\
\hline \multicolumn{2}{|l|}{ Drug use } \\
\hline No & 1.00 \\
\hline Yes & $1.81(1.57-2.09)$ \\
\hline \multicolumn{2}{|l|}{ Exercise } \\
\hline No & 1.00 \\
\hline 1-4 times/wk & $1.05(0.98-1.13)$ \\
\hline 5 times/wk & $1.10(1.01-1.20)$ \\
\hline
\end{tabular}

Table 2. Continued

\begin{tabular}{lc}
\hline \multicolumn{1}{c}{ Variable } & E-cigarette experience \\
\hline Self-rated health & \\
Poor & 1.00 \\
Normal & $1.00(0.89-1.12)$ \\
Good & $1.03(0.93-1.14)$ \\
Obesity & \\
Underweight & 1.00 \\
Normal & $0.92(0.82-1.02)$ \\
Overweight & $0.91(0.71-1.17)$ \\
Obese & $0.79(0.69-0.91)$ \\
Year & \\
2011 & 1.00 \\
2012 & $0.76(0.69-0.84)$ \\
2013 & $0.69(0.61-0.77)$ \\
2014 & $1.78(1.59-1.99)$
\end{tabular}

Values are presented as odds ratio (95\% confidence interval). Values are results from multiple logistic regression.

*Pick up cigarettes on the road, get from adults, or find at home.

Table 3. Results of subgroup analysis between possibility of purchasing cigarettes and e-cigarette experience by sex*

\begin{tabular}{lcc}
\hline \multicolumn{1}{c}{ Variable } & Male & Female \\
\hline Possibility of purchasing cigarettes & & \\
$\quad$ Have not tried & $0.73(0.64-0.82)$ & $0.84(0.65-1.09)$ \\
Impossible & 1.00 & 1.00 \\
Difficult & $1.10(0.96-1.27)$ & $0.90(0.65-1.25)$ \\
Easy & $1.20(1.06-1.36)$ & $1.15(0.89-1.48)$ \\
\hline
\end{tabular}

Values are presented as odds ratio (95\% confidence interval). Values are results from multiple logistic regression.

*Adjusted for household economic status, academic performance, money spent per week, sexual activity, alcohol use, drug use, exercise, perceived health, obesity, year, number of cigarettes per day, cigarette access method, smoking cessation trial, and anti-smoking education.

playing problematic behaviors such as sexual activity and drug use were significantly associated with e-cigarette experience.

Table 3 shows the results of the subgroup analysis of the possibility of purchasing cigarettes and e-cigarette experience by sex. An easy possibility of purchasing cigarettes was significantly associated with ecigarette experience in the male group only (OR, 1.20; 95\% CI, 1.061.36). The easier the possibility of purchasing cigarettes, the higher were the odds of e-cigarette experience.

Table 4 shows the results of the subgroup analysis of the possibility of purchasing cigarettes by age using survey logistic regression adjusted for all independent variables. A survey logistic regression was conducted to identify the association between the possibility of purchasing cigarettes and e-cigarette experience by age group. The reference is impossible to purchase cigarettes. Compared to the reference, the perception of it being easy to purchase cigarettes increased the odds of ecigarette experience among males aged 12-15 or 17 years compared to the perception of it being impossible to purchase cigarettes. 
Table 4. Results of the subgroup analysis between possibility of purchasing cigarettes and e-cigarette experience by age*

\begin{tabular}{lcccccr}
\hline \multicolumn{1}{c}{ Variable } & \multicolumn{5}{c}{ Age (y) } \\
\cline { 2 - 6 } & $12-13$ & 14 & 15 & 16 & 17 \\
\hline Possibility of purchasing cigarettes & & & & & \\
$\quad$ Have not tried & $0.56(0.40-0.78)$ & $0.64(0.48-0.85)$ & $0.64(0.51-0.81)$ & $0.56(0.44-0.70)$ & $0.68(0.52-0.89)$ & $0.61(0.40-0.94)$ \\
$\quad$ Impossible & 1.00 & 1.00 & 1.00 & 1.00 & 1.00 & 1.00 \\
$\quad$ Difficult & $1.16(0.77-1.76)$ & $1.33(0.94-1.87)$ & $0.94(0.71-1.23)$ & $1.03(0.79-1.34)$ & $1.42(1.05-1.92)$ & $1.01(0.64-1.57)$ \\
Easy & $1.88(1.33-2.65)$ & $1.42(1.06-1.91)$ & $1.33(1.07-1.66)$ & $1.22(0.98-1.53)$ & $1.38(1.07-1.79)$ & $1.05(0.74-1.48)$ \\
\hline
\end{tabular}

Values are presented as odds ratio (95\% confidence interval). Values are results from multiple logistic regression.

*Adjusted for sex, household economic status, academic performance, spending money per week, sexual activity, alcohol use, drug use, exercise, perceived health, obesity, year, number of cigarettes per day, cigarette access method, smoking cessation trial, and anti-smoking education.

\section{DISCUSSION}

This study provides evidence related to e-cigarette experience in a large sample of Korean adolescents. Our primary purpose was to investigate the association between the possibility of purchasing cigarettes and e-cigarette experience among currently smoking adolescents in a nationally representative sample of the general population of South Korea.

There are many reasons people use e-cigarettes for. One such reason is to quit smoking. ${ }^{12)}$ According to a recent New Zealand study of adults, ${ }^{21)}$ the most common reasons for current smokers to try e-cigarettes were to quit smoking completely or use them occasionally as a substitute product. Similarly, for ex-smokers, the most common reason to try e-cigarettes was to quit smoking. However, there was no difference in successful quitting rates between e-cigarette users and nonusers in the United States, the United Kingdom, Canada, and Australia. ${ }^{22,23)}$ Lee et al. ${ }^{24)}$ in 2014 from Korea showed that e-cigarette users smoke more conventional cigarettes per day and mentioned that there is no evidence that e-cigarettes help smokers quit smoking. Therefore, e-cigarette use requires control to help reduce the smoking rate in adolescents. Similar to the results of the current study, Carroll Chapman and $\mathrm{Wu}^{14)}$ in 2014 reported that young adults did not use e-cigarettes to quit smoking. Lee et al. ${ }^{13)}$ in 2017 reported a positive correlation between e-cigarette use and cigarette smoking in Korean adolescents.

Our results show that adolescents that find it easy to purchase cigarettes were more likely to have e-cigarette experience. Interestingly, the likelihood of adolescent e-cigarette experience of those who perceived it easy to purchase cigarettes decreased as age increased. Additionally, the likelihood of middle school students (aged 12-15 years) having e-cigarette experience was higher than that of high school students (aged 16-18 years) after the adjustment of all covariates. This result is worrisome from the point of view that e-cigarettes act as a gateway to smoking regular cigarettes. ${ }^{12)}$

Although it is illegal to sell tobacco to adolescents in Korea, adolescents who smoke regularly purchase their tobacco from offline stores or the internet and then share their cigarettes with peers, becoming the primary source for new smokers. ${ }^{25,26)}$ Adolescents then share their sources of cigarettes with their peers. ${ }^{27)}$ In a similar way, online and offline e-cigarette stores in Korea should check customers' ages and en- sure that only adults can buy e-cigarettes. However, adolescents' main sources of e-cigarettes are offline e-cigarette stores, followed by online stores. ${ }^{28)}$ They use friends' or family members' online accounts or ask adults to buy e-cigarettes. Furthermore, $32 \%$ of offline e-cigarettes stores did not check age, even when adolescents tried to buy e-cigarettes, making it easy for them to purchase e-cigarettes.

Studies of tobacco stores that sell cigarettes to adolescents have shown that their perceptions about the possibility of purchasing cigarettes may become worse when stores do not comply with regulations. ${ }^{29,30)}$ While the government can prosecute offline stores that sell tobacco to adolescents, it is difficult to closely monitor the activities of online stores. Consequently, laws that ban online and offline sales of ecigarettes to adolescents must be strengthened immediately. In the United States, a combination of excise taxation, litigation against tobacco companies, and the enforcement of laws prohibiting the sale of tobacco products to minors have increased the cost of and difficulty obtaining tobacco products. ${ }^{31,32)}$ A price increase seems a necessary and rational way to dissuade adolescents from initially trying tobacco products and subsequently developing a lifetime nicotine addiction. ${ }^{33)}$

Although our results revealed that anti-smoking education is insignificant, we recommend that anti-smoking education be strengthened. Attitudes about smoking were the key factor associated with smoking accessibility and purchasing behavior among adolescents. Likewise, a previous study showed that adolescents with positive attitudes about smoking became smokers. ${ }^{34)}$ Moreover, although knowledge might not be directly related to cigarette-purchasing behavior, the greater the adolescents' level of knowledge about tobacco hazards, the less likely they were to perceive cigarettes as accessible. Therefore, we recommend that health educators aim to change adolescents' attitudes about smoking, which can in turn positively influence their perception of tobacco access as well as their purchasing behaviors. School-based programs should involve and educate parents. Encouraging parents to monitor their adolescents and be unambiguously strict in their own attitudes about tobacco use will help decrease adolescents' susceptibility and access to tobacco. ${ }^{33)}$

This study has strengths and limitations. One strength is that the survey sample may be representative of the adolescent population under study. Specifically, because the study obtained a large sample of the target population, the results can be generalized to the South Kore- 
an adolescent population. Nevertheless, we acknowledge the possibility of sample bias. This study was based on a cross-sectional analysis; thus, we cannot determine causation between the independent and dependent variables. Second, this study used secondary data that was not specifically designed to collect information about adolescents' perceptions of tobacco product accessibility. As a result, several factors associated with adolescents' perceptions of cigarette accessibility, such as the tobacco retailers' selling behavior and the channels utilized to acquire cigarettes, were not included. A third limitation is that the respondents' self-reporting of the main independent variables and covariates included in the analysis were subjective and potentially imperfect measures. Consequently, recall bias is possible.

In conclusion, the easy possibility of purchasing cigarettes was positively associated with e-cigarette experience. The likelihood of adolescents' e-cigarette experience was related to their possibility of purchasing cigarettes, which decreased as age increased. As a result, policymakers need to strengthen restrictions to prevent adolescents' access to online and offline purchases of e-cigarettes and cigarettes. Additionally, health educators must further consider ways to change adolescents' attitudes about smoking.

\section{CONFLICT OF INTEREST}

No potential conflict of interest relevant to this article was reported.

\section{ACKNOWLEDGMENTS}

The English in this paper has been checked by at least two professional language editors, both native speakers of English. This paper was supported by Eulji University in 2016 (EJBS-16-04).

\section{REFERENCES}

1. Moh'd Al-Mulla A, Abdou Helmy S, Al-Lawati J, Al Nasser S, Ali Abdel Rahman S, Almutawa A, et al. Prevalence of tobacco use among students aged 13-15 years in Health Ministers' Council/Gulf Cooperation Council Member States, 2001-2004. J Sch Health 2008;78:337-43.

2. Nohlert E, Tegelberg A, Tillgren P, Johansson P, Rosenblad A, Helgason AR. Comparison of a high and a low intensity smoking cessation intervention in a dentistry setting in Sweden: a randomized trial. BMC Public Health 2009;9:121.

3. Murray CJ, Lopez AD. Global mortality, disability, and the contribution of risk factors: Global Burden of Disease Study. Lancet 1997;349:1436-42.

4. Jee SH, Lee JK, Kim IS. Smoking-attributable mortality among Korean adults: 1981-2003. Korean J Epidemiol 2006;28:92-9.

5. Lantz PM, Jacobson PD, Warner KE, Wasserman J, Pollack HA, Berson $\mathrm{J}$, et al. Investing in youth tobacco control: a review of smoking prevention and control strategies. Tob Control 2000;9:47-63.

6. Preventing tobacco use among young people: a report of the Surgeon General: executive summary. MMWR Recomm Rep 1994;43(RR-4):110.
7. Organization for Economic Cooperation and Development, World Health Organization. Health at a glance: Asia/Pacific. Paris: OECD Publishing; 2016.

8. Korea Centers for Disease Control and Prevention. Trends in adolescent tobacco use [Internet]. Cheongju: Korea Centers for Disease Control and Prevention; 2017 [cited 2017 May 1]. Available from: http:// www.index.go.kr/potal/main/EachDtlPageDetail.do?idx_cd=2829.

9. Korea Centers for Disease Control and Prevention. Statistics of 10th the Korea Youth Risk Behavior Web-based Survey. Cheongju: Korea Centers for Disease Control and Prevention; 2014.

10. Brown J, West R, Beard E, Michie S, Shahab L, McNeill A. Prevalence and characteristics of e-cigarette users in Great Britain: findings from a general population survey of smokers. Addict Behav 2014;39:1120-5.

11. Bell K, Keane H. Nicotine control: e-cigarettes, smoking and addiction. Int J Drug Policy 2012;23:242-7.

12. West R, Brown J. Electronic cigarettes: fact and faction. Br J Gen Pract 2014;64:442-3.

13. Lee JA, Lee S, Cho HJ. The relation between frequency of e-cigarette use and frequency and intensity of cigarette smoking among South Korean adolescents. Int J Environ Res Public Health 2017;14:E305.

14. Carroll Chapman SL, Wu LT. E-cigarette prevalence and correlates of use among adolescents versus adults: a review and comparison. J Psychiatr Res 2014;54:43-54.

15. U.S. Department of Health and Human Services. E-cigarette use among youth and young adults: a report of the Surgeon General. Atlanta (GA): U.S. Department of Health and Human Services, Centers for Disease Control and Prevention, National Center for Chronic Disease Prevention and Health Promotion, Office on Smoking and Health; 2016.

16. Turner KM, Gordon J, Young R. Cigarette access and pupil smoking rates: a circular relationship? Health Promot Int 2004;19:428-36.

17. Leatherdale ST, Strath JM. Tobacco retailer density surrounding schools and cigarette access behaviors among underage smoking students. Ann Behav Med 2007;33:105-11.

18. Doubeni CA, Li W, Fouayzi H, Difranza JR. Perceived accessibility as a predictor of youth smoking. Ann Fam Med 2008;6:323-30.

19. Doubeni CA, Li W, Fouayzi H, DiFranza JR. Perceived accessibility of cigarettes among youth: a prospective cohort study. Am J Prev Med 2009;36:239-42.

20. Barlow SE; Expert Committee. Expert committee recommendations regarding the prevention, assessment, and treatment of child and adolescent overweight and obesity: summary report. Pediatrics 2007;120 Suppl 4:S164-92.

21. Li J, Newcombe R, Walton D. The prevalence, correlates and reasons for using electronic cigarettes among New Zealand adults. Addict Behav 2015;45:245-51.

22. Regan AK, Promoff G, Dube SR, Arrazola R. Electronic nicotine delivery systems: adult use and awareness of the 'e-cigarette' in the USA. Tob Control 2013;22:19-23.

23. Adkison SE, O'Connor RJ, Bansal-Travers M, Hyland A, Borland R, Yong $\mathrm{HH}$, et al. Electronic nicotine delivery systems: international tobacco control four-country survey. Am J Prev Med 2013;44:207-15.

24. Lee S, Grana RA, Glantz SA. Electronic cigarette use among Korean adolescents: a cross-sectional study of market penetration, dual use, and relationship to quit attempts and former smoking. J Adolesc 
Health 2014;54:684-90.

25. Forster J, Chen V, Blaine T, Perry C, Toomey T. Social exchange of cigarettes by youth. Tob Control 2003;12:148-54.

26. Park SW. National policy for adolescent smoking prevention and cessation. Health Welf Policy Forum 2007;129:22-34.

27. Park SH. Smoking and adolescent health. Korean J Pediatr 2011;54:401-4.

28. Ministry of Gender Equality and Family. Analysis report on the use of media and the status of harmful environment for youth in 2016. Seoul: Ministry of Gender Equality and Family; 2016.

29. Johnston LD, O'malley PM, Terry-McElrath YM. Methods, locations, and ease of cigarette access for American youth, 1997-2002. Am J Prev Med 2004;27:267-76.

30. Osaki Y, Tanihata T, Ohida T, Minowa M, Wada K, Suzuki K, et al. Adolescent smoking behaviour and cigarette brand preference in Japan.
Tob Control 2006; 15:172-80.

31. Liang L, Chaloupka FJ. Differential effects of cigarette price on youth smoking intensity. Nicotine Tob Res 2002;4:109-14.

32. Sung HY, Hu TW, Ong M, Keeler TE, Sheu ML. A major state tobacco tax increase, the master settlement agreement, and cigarette consumption: the California experience. Am J Public Health 2005;95:10305.

33. Albert DA, Severson HH, Andrews JA. Tobacco use by adolescents: the role of the oral health professional in evidence-based cessation programs. Pediatr Dent 2006;28:177-87.

34. Huang HL, Hsu CC, Peng WD, Yen YY, Chen T, Hu CY, et al. Analysis of influential factors associated with the smoking behavior of aboriginal schoolchildren in remote Taiwanese mountainous areas. J Sch Health 2012;82:318-27. 